\title{
Orbit to Orbit Intersatellite Optical Wireless Communications with Customized Information Security Management System
}

\author{
Abd El-Naser A. Mohammed \\ Electronics and Electrical \\ Communications Engineering \\ Department, Faculty of Electronic \\ Engineering, Menouf 32951, \\ Menoufia University.
}

\author{
Ahmed Nabih Zaki Rashed \\ Electronics and Electrical \\ Communications Engineering \\ Department, Faculty of Electronic \\ Engineering, Menouf 32951, \\ Menoufia University.
}

\author{
Mostafa Moftah Ali \\ Electronics and Electrical \\ Communications Engineering \\ Department, Faculty of Electronic \\ Engineering, Menouf 32951, \\ Menoufia University.
}

\author{
Ehab Salah El-dien \\ Electronics and Electrical \\ Communications Engineering \\ Department, Faculty of Electronic \\ Engineering, Menouf 32951, \\ Menoufia University.
}

\begin{abstract}
This paper has presented the effect of erbium doped fiber amplifier (EDFA) as a pre and post amplifier in intersatellite wireless optical communication system and it is compared with semiconductor optical amplifier (SOA) as pre and post amplifiers in the same communication system design. The study is analyzed the effect of changing propagation distances between satellites spacing. Gain and bit error rate are investigated against the transmitter input power increase in both systems. The comparison between EDFA and SOA in intersatellite optical wireless communication system with different input parameters (input power and physical amplifier dimensions) is demonstrated. We are building information security management system using FEC, which is a digital signal processing technique used to enhance data reliability.
\end{abstract}

\section{Introduction}

Optical wireless communication in satellite intercommunication is an effective way of communication between satellite systems, the great distances between satellites are the main attenuation factor, there are other factors like cosmic rays, or pink noise that can affect the communication, but the effect is very small and can be neglected in this study [1]. In this paper we had investigated the performance of the communication system with having pre and post optical amplifiers EDFA, and SOA and compare the performance in each model. Then security component was added FEC as coder and decoder to code the signal traveling in space between satellites we reached in this study to have optimum inter satellite communication system reaching $10000 \mathrm{Km}$ with $\mathrm{Q}$ factor 30 and BER reached to zero. Related work was done to achieve communication system of maximum of $5000 \mathrm{~km}$ to $7000 \mathrm{~km}$ using EDFA as pre and post amplifiers [2] and [3] but was not touching the security part. In this work the results of the verified. Enhancing an optical communication system to overcome the problem of the distance and enhance the quality factor was the goal of this paper. Using optical amplifiers was the solution to enhance this communication, and with adjusting some of the performance parameters of the EDFA optical amplifiers, the placement of amplifiers as pre and post amplifier enhance the gain of the communication system [4], Comparing the use of EDFA verses SOA, was to demonstrate the gain at the output in each communication system in the same circumstances and near input parameters. The reason to use SOA against EDFA was that SOA has the smaller physical dimensions and is easier to be deployed in communication systems, on the other hand, EDFA is a reliable optical amplifier and is commonly used [5]. In this work input power was chosen in practical range $(10 \mathrm{~mW}, 15 \mathrm{~mW}$ and $20 \mathrm{~mW})$, optiwave 7.0 simulator was used to examine the output to demonstrate the change of the input parameters and the resulted output parameters [6], using FEC because it is FEC codes generally detect the last set of bits to determine the decoding of a small handful of bits[7].

\section{Proposed work: System Structure simulation} proposed model

The communication system designed to achieve a distance of $5000 \mathrm{Km}$ which is the minimum distances between satellites orbits and distance $10000 \mathrm{~km}$ was targeted as an enhancement. The following figures illustrate the designs.

\subsection{Transmitter and Receiver components}

As demonstrated in figures (1) the system had the EDFA to enhance the output quality factor and bit error rate in distance between satellites of $1000 \mathrm{~km}$. In figure (2) SOA was used to enhance the output parameters. Both systems composed of Pseudo-Random Bit Sequence Generator, in case of system in figure (1), it was adjusted to bit rate (10GB, 20GB and $25 \mathrm{~GB})$ and EDFA length used was $(5 \mathrm{~m}$ and $10 \mathrm{~m}$ ), Mach-Zehnder Modulator, NRZ Pulse Generator, Continues Wave laser diode adjusted in each system to $(10 \mathrm{~mW}, 15 \mathrm{~mW}$ and $20 \mathrm{~mW})$. In figure (2) EDFA pre amplifier was changed by Traveling wave (TW) SOA. The OWC Channel was used and changed the optical antenna aperture area $(15 \mathrm{~cm}$ and $20 \mathrm{~cm})$ to demonstrate the effect of changing it on the gain at the output. Receiver components was common in both systems, having photo detector APD, Low Pass Bessel Filter, and 3R Regenerator, post amplifier EDFA in figure (1) was changed by (TW) SOA in figure (2). Starting with EDFA amplifier as in first communication system illustrated in figure (1), there are different methods 
of using different pumping power in communication systems design, which they are (forward pumping), or (backward pumping) or (bidirectional pumping) the pumping power can achieve optimum output signal, the scope of this work was using forward pumping power only in this communication system, it was demonstrated in the study the effect of changing the values of forward pumping power using values of (1Watt and 2Watt) in each case of varying the input power of the system, and with changing the distance between the transmitter and the receiver which was $(5000 \mathrm{Km}$ and $10000 \mathrm{~km})$ which represents two different orbit distances between two satellites. In the SOA system shown in figure (2), the input power was adjusted to the same values of the EDFA system which was $(10 \mathrm{~mW}, 15 \mathrm{~mW}$ and $20 \mathrm{~mW}$ ), and the parameters of the amplifier was kept as the default values of the simulator, also the distance was adjusted to $(1000 \mathrm{~km}, 5000 \mathrm{~km}$ and $10000 \mathrm{~km})$, the reason of adding the distance value of $(1000 \mathrm{~km})$ in this system is to study lower distance performance against using SOA as pre and post amplifiers in such communication system.

\section{Simulation Results and Discussions}

For system in Figure (1), which EDFA was used as pre and post amplifiers the input operating parameter were shown in the following Table (1):

Table (1) system operating parameters for EDFA

\begin{tabular}{|l|l|}
\hline Operating parameters & Value \\
\hline Signal Input power & $20 \mathrm{~mW}$ \\
\hline Signal wavelength & $\begin{array}{l}1553 \mathrm{~nm} \text { (constant } \\
\text { Value) }\end{array}$ \\
\hline Frequency spacing & $\begin{array}{l}0.5 \mathrm{~nm} \mathrm{(constant} \\
\text { Value) }\end{array}$ \\
\hline $\begin{array}{l}\text { Distance between Tx and } \\
\text { Rx }\end{array}$ & $10000 \mathrm{~km}$ \\
\hline EDFA length and backward & $\begin{array}{l}980,10,15 \mathrm{~m} \\
\text { constant (value) }\end{array}$ \\
\hline $\begin{array}{l}\text { Forward and } \\
\text { Pumping wavelength }\end{array}$ & $1,2 \mathrm{~W}$ \\
\hline Forward Pumping power & $15,20 \mathrm{~cm}$ \\
\hline Telescope aperture &
\end{tabular}

The following figures describes the input parameters changes and the accordance output parameters results. As seen in figures (3) to (6) it was used Signal Input power 20 $\mathrm{mW}$, Distance $10000 \mathrm{Km}$, EDFA length were varied from $5 \mathrm{~m}$ to $15 \mathrm{~m}$, Forward Pumping power $2 \mathrm{~W}$ and Telescope aperture $15 \mathrm{~cm}$, the resultant Q factor results ware approx. 21, 19 and 20, and BER was 3.6 e-100, 1.09 e-088 and 8.24 e-097. In figure (7) the optimum configuration for (10 GB) input bit rate - Signal Input power 20mW, Distance 10000 $\mathrm{Km}$, EDFA length $5 \mathrm{~m}$ Forward Pumping power, 2W, Telescope aperture $20 \mathrm{~cm}$, the Q was 38.7 and BER is zero. In figure (8) bit rate (20GB), Signal Input power $20 \mathrm{~mW}$, Distance $10000 \mathrm{Km}$, EDFA length 5m, Forward Pumping power $2 \mathrm{~W}$, Telescope aperture $20 \mathrm{~cm}$. In Figure (9) bite rate (25GB) Signal Input power 20mW, Distance $10000 \mathrm{Km}$, EDFA length $5 \mathrm{~m}$, Forward Pumping power $2 \mathrm{~W}$, Telescope aperture $20 \mathrm{~cm}$.

\section{Analyzing Results and Evaluating System Performance}

As shown in figures (3) to (6), it was investigated the Q factor and BER, with increasing of EDFA length, for the targeted distance range which is $10000 \mathrm{~km}$. The input power of 20 mWatt, EDFA forward pumping power of 2 Watt, telescope aperture of $15 \mathrm{~cm}$, and the EDFA length was varied from $5 \mathrm{~m}$ to $20 \mathrm{~m}$ with $5 \mathrm{~m}$ increment, and input bit rate was $10 \mathrm{~GB}$ in these figures. The results demonstrated in figures (10) to (13) respectively.

It was shown that the maximum $Q$ factor in these figures were 14.0261 at input power of $20 \mathrm{mWatt}$, as the min BER was 5.08849E-45. The quality factor was decreased as the distance increased. Comparing between $\mathrm{Q}$ factors in the range of $5000 \mathrm{~km}$ and $10000 \mathrm{~km}$, it was found that although the changes in $\mathrm{Q}$ factor is minor changes, when it was increasing the input power, but the difference of the value of $\mathrm{Q}$ factor in the range of $10000 \mathrm{~km}$ compared of the Q factor in the range of $5000 \mathrm{~km}$ is noticeably reduced, and on the contrary of that, the BER increase with the increase of range of distance. In figure (7) Optimum configuration for (10 GB) bit rate as an input, and using Signal Input power 20mW, Distance $10000 \mathrm{Km}$, EDFA length 5m Forward Pumping power, 2W, Telescope aperture $20 \mathrm{~cm}$, the $\mathrm{Q}$ factor was maximum value of 38.7676 and BER was zero. In figures (8) to (9) the Signal Input power was $20 \mathrm{~mW}$, Distance $10000 \mathrm{Km}$, EDFA length 5m, Forward Pumping power $2 \mathrm{~W}$, Telescope aperture $20 \mathrm{~cm}$, it was investigated the $\mathrm{Q}$ factor and BER with changing input bit rate to $20 \mathrm{~GB}$ and $25 \mathrm{~GB}$ respectively the $\mathrm{Q}$ factor were for these figures 11.1744 for $20 \mathrm{~GB}$ input bit rate, and 4.11404 for $25 \mathrm{~GB}$ input bit rate, the BER was increased to 2.42441E-29, and 1.89264E-05. It was noticed that the effect of increasing the EDFA length was decreasing the $\mathrm{Q}$ factor for the lengths of $5 \mathrm{~m}$ to $10 \mathrm{~m}$, but after increasing the length to $15 \mathrm{~m}$ and 20 $\mathrm{m}$ the $\mathrm{Q}$ factor increased again, in the opposite the increase of EDFA length was increasing the BER until the maximum at $10 \mathrm{~m}$, then the BER had decreased after $10 \mathrm{~m}$ to a steady state. The explanation of this phenomena, is, as the fiber length increase in the EDFA, the dispersion losses in the fiber increase, until threshold in which the dispersion losses becomes equal to the amplification factor due to the doped erbium, this will cause decrease in the $\mathrm{Q}$ factor and increase in BER as the EDFA length increase, until the $\mathrm{Q}$ factor reaches zero [8].

\subsection{SOA system results}

For system in Figure (2), which SOA was used as pre and post amplifiers the input operating parameter were shown in the following Table (2):

Table (2) system operating parameters for SOA

\begin{tabular}{|l|l|}
\hline $\begin{array}{l}\text { Operating } \\
\text { parameters }\end{array}$ & Value \\
\hline Signal Input power & $10,15,20 \mathrm{~mW}$ \\
\hline Signal wavelength & $\begin{array}{l}1553 \mathrm{~nm} \\
\text { Value) }\end{array}$ \\
\hline Frequency spacing & $0.5 \mathrm{~nm}$ (constant Value) \\
\hline $\begin{array}{l}\text { Distance between } \\
\text { Tx. and Rx. }\end{array}$ & $1000,5000,10000 \mathrm{~km}$ \\
\hline Telescope aperture & $15,20 \mathrm{~cm}$ \\
\hline
\end{tabular}




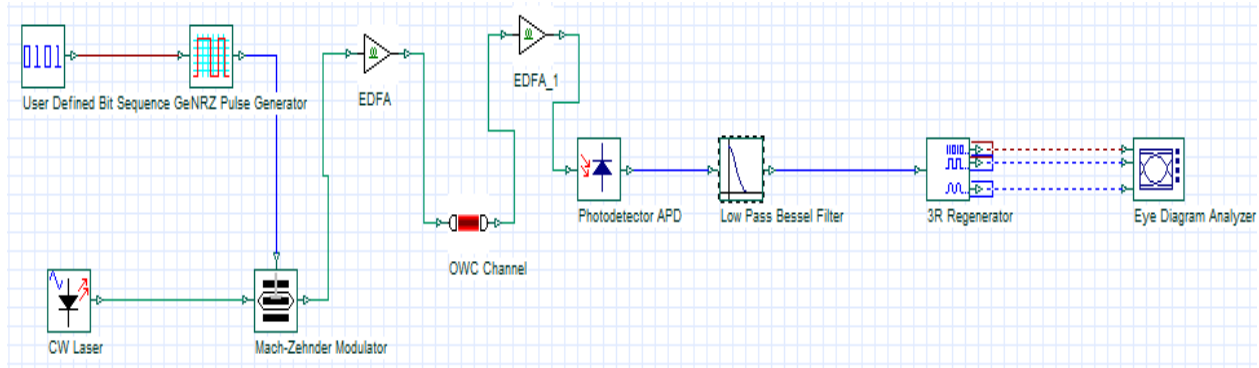

Fig. 1 Model of system design using EDFA

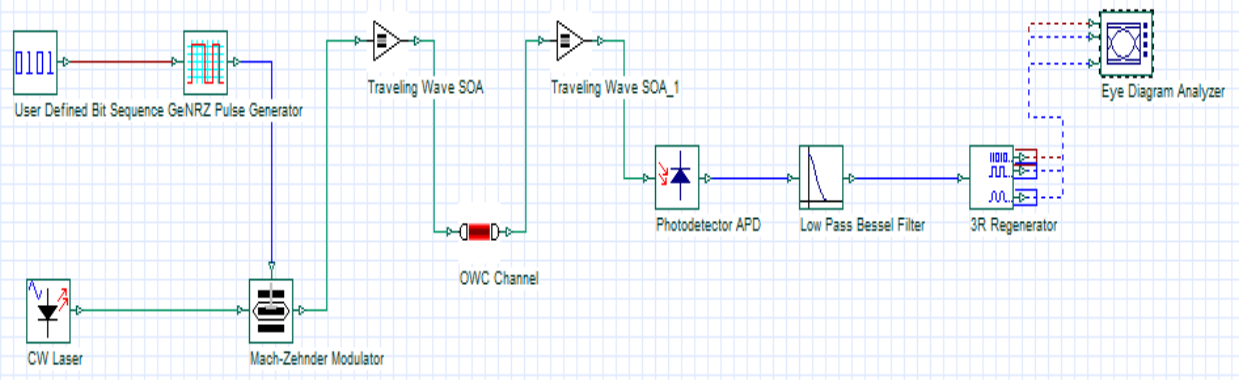

Fig. 2 Model of system design using SOA

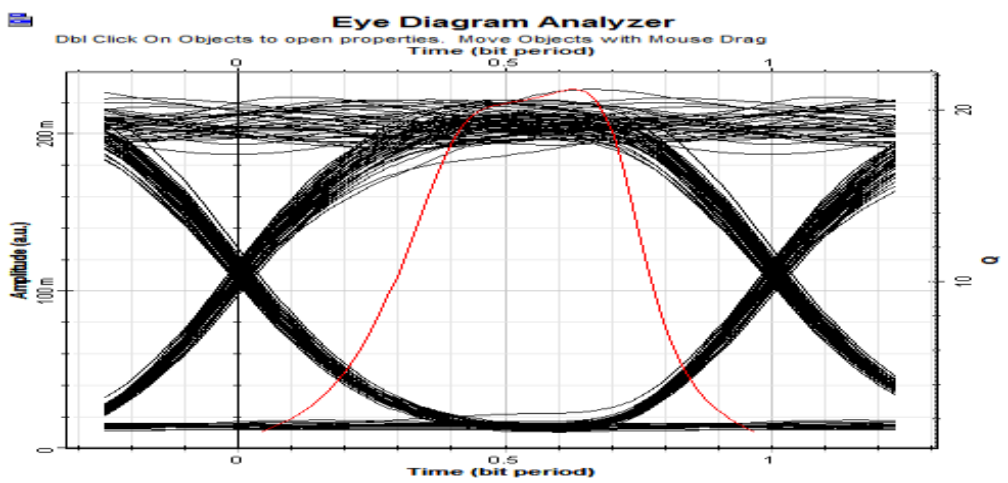

\begin{tabular}{|l|r|}
\hline \multicolumn{1}{|c|}{ Analysis } & \\
\hline Max. Q Factor & 21.2077 \\
\hline Min. BER & $3.67475 e-100$ \\
\hline Eye Height & 0.165827 \\
\hline Threshold & 0.0545072 \\
\hline Decision Inst. & 0.625 \\
\hline \hline
\end{tabular}

Fig. 3 Signal Input power $20 \mathrm{~mW}$, Distance $10000 \mathrm{Km}$, EDFA length 5m, Forward Pumping power $2 \mathrm{~W}$ and Telescope aperture $15 \mathrm{~cm}$

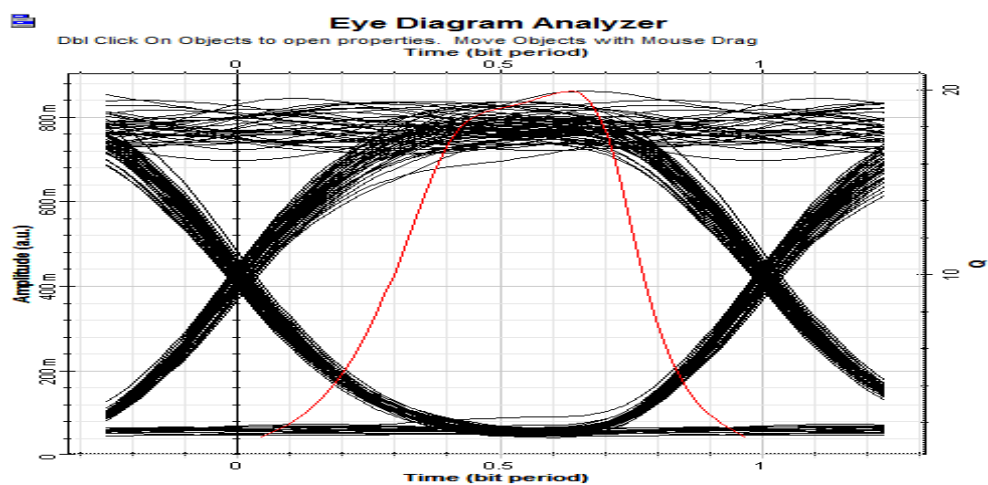

\begin{tabular}{l}
\multicolumn{1}{c|}{ Analysis } \\
\begin{tabular}{|l|r|}
\hline Max. Q Factor & 19.9262 \\
\hline Min. BER & $1.09617 e-088$ \\
\hline Eye Height & 0.610506 \\
\hline Threshold & 0.212923 \\
\hline Decision Inst. & 0.640625 \\
\hline \hline
\end{tabular}
\end{tabular}

Fig. 4 Signal Input power $20 \mathrm{~mW}$, Distance, $10000 \mathrm{Km}$, EDFA length $10 \mathrm{~m}$, Forward Pumping power, 2W, Telescope aperture, $15 \mathrm{~cm}$ 


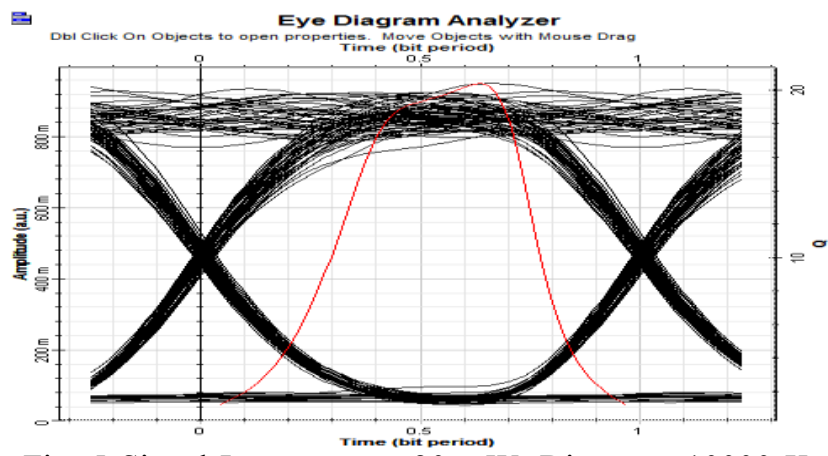

\begin{tabular}{l}
\multicolumn{1}{c|}{ Analysis } \\
\begin{tabular}{|l|r|}
\hline Max. Q Factor & 20.3766 \\
\hline Min. BER & $1.22271 e-092$ \\
\hline Eye Height & 0.678286 \\
\hline Threshold & 0.231993 \\
\hline Decision Inst. & 0.640625 \\
\hline \hline
\end{tabular}
\end{tabular}

Fig. 5 Signal Input power, $20 \mathrm{~mW}$, Distance $10000 \mathrm{Km}$, EDFA length, 15m, Forward Pumping power $2 \mathrm{~W}$, Telescope aperture $15 \mathrm{~cm}$

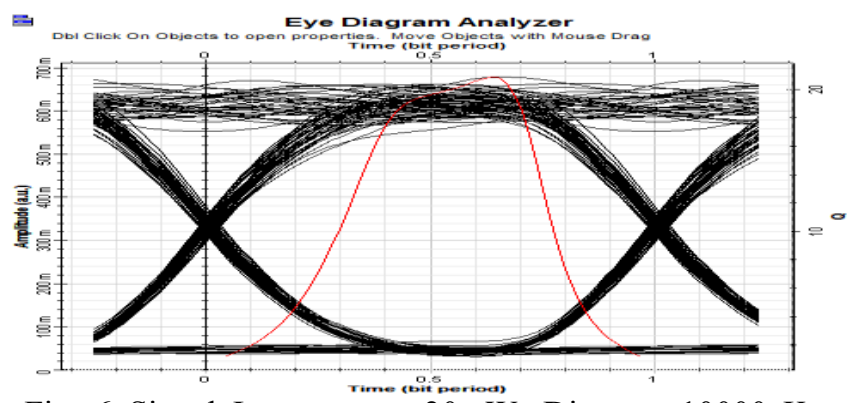

Fig. 6 Signal Input power $20 \mathrm{~mW}$, Distance $10000 \mathrm{Km}$, EDFA length 20m, Forward Pumping power 2W,Telescope aperture $15 \mathrm{~cm}$

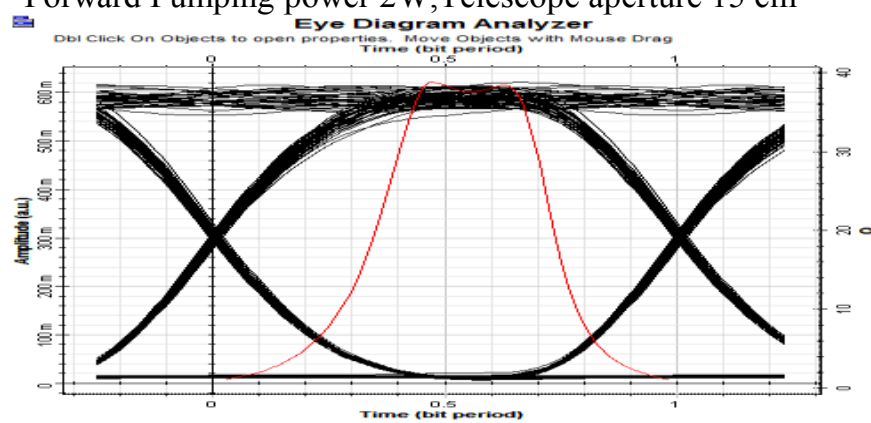

Fig. 7 Optimum configuration for (10 GB) input bit rate - Signal Input power $20 \mathrm{~mW}$, Distance $10000 \mathrm{Km}$, EDFA length 5m Forward Pumping power, 2W, Telescope aperture $20 \mathrm{~cm}$

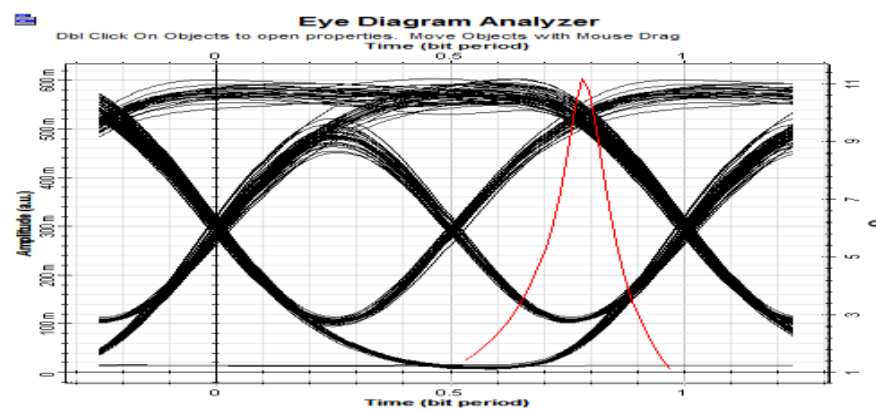

Fig. 8 bit rate (20GB), Signal Input power 20mW, Distance $10000 \mathrm{Km}$, EDFA length 5m, Forward Pumping power $2 \mathrm{~W}$, Telescope aperture $20 \mathrm{~cm}$

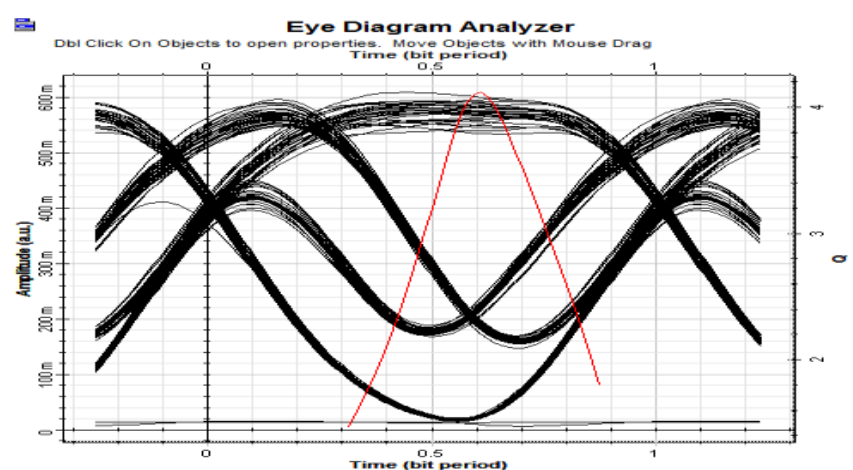

\begin{tabular}{|l|r|}
\multicolumn{1}{|c|}{ Analysis } & \multicolumn{1}{c|}{} \\
\begin{tabular}{|l|r|}
\hline Max. Q Factor & 4.11404 \\
\hline Min. BER & $1.89264 \mathrm{e}-005$ \\
\hline Eye Height & 0.11596 \\
\hline Threshold & 0.502773 \\
\hline Decision Inst. & 0.609375 \\
\hline \hline
\end{tabular}
\end{tabular}

Fig. 9 bite rate (25GB) Signal Input power 20mW, Distance 10000 Km, EDFA 


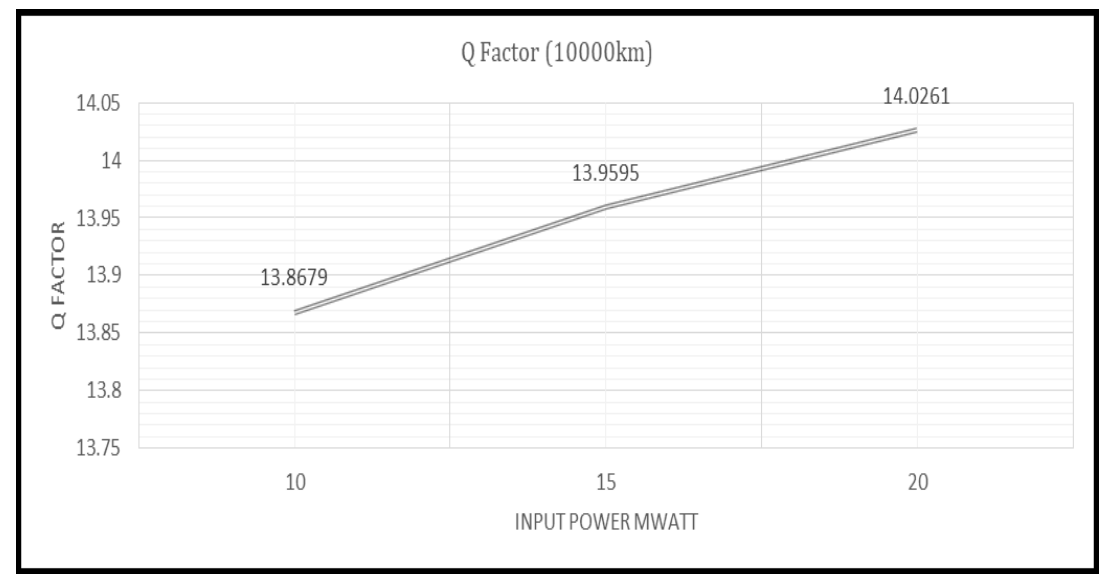

Fig. 10 Q factor Vs. Input power increase

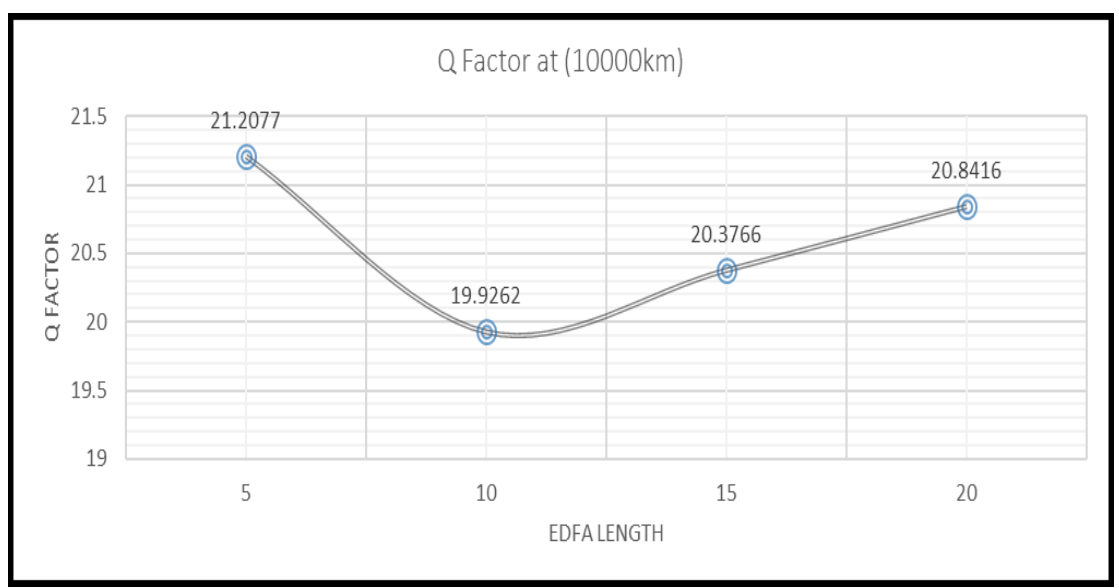

Fig. 11 BER Vs. input power increase

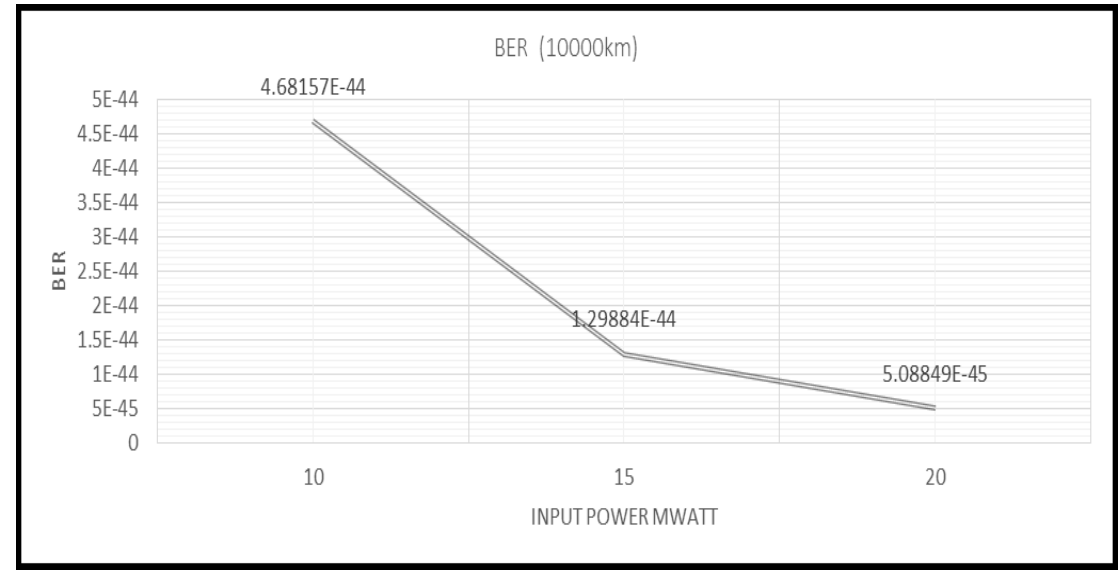

Fig. 12 Q factor with different EDFA lengths

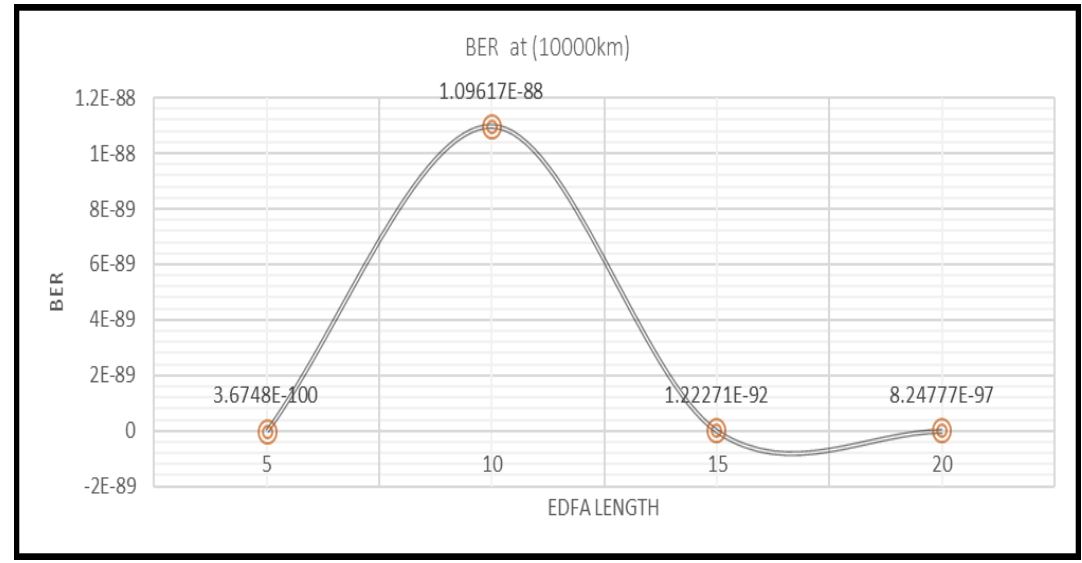

Fig. 13 BER with different EDFA lengths 


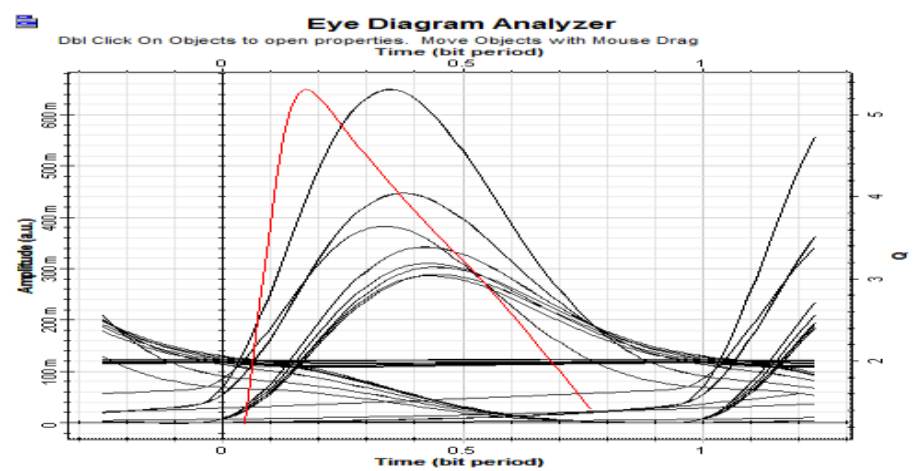

\begin{tabular}{|l|r|}
\multicolumn{1}{|c|}{ Analysis } & \multicolumn{1}{|c|}{} \\
\hline Max. Q Factor & 5.30891 \\
\hline Min. BER & $5.34074 \mathrm{e}-008$ \\
\hline Eye Height & 0.172784 \\
\hline Threshold & 0.431478 \\
\hline Decision Inst. & 0.171875 \\
\hline
\end{tabular}

Fig. 14 Signal Input power 20mW, Distance $1000 \mathrm{Km}$, Telescope aperture $15 \mathrm{~cm}$

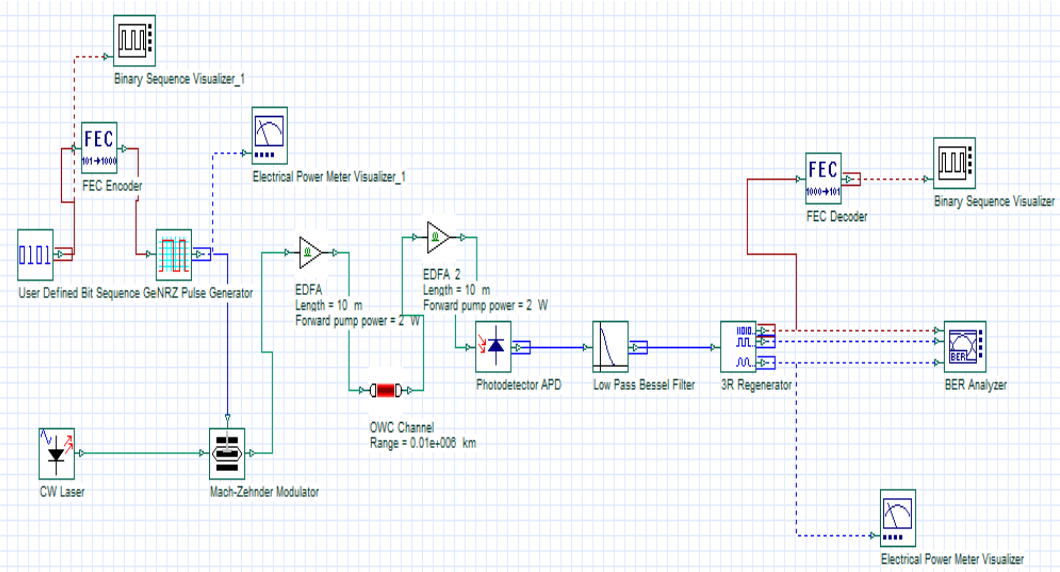

Fig. 15 system design with implementing FEC

Table 3 results with using FEC in the system

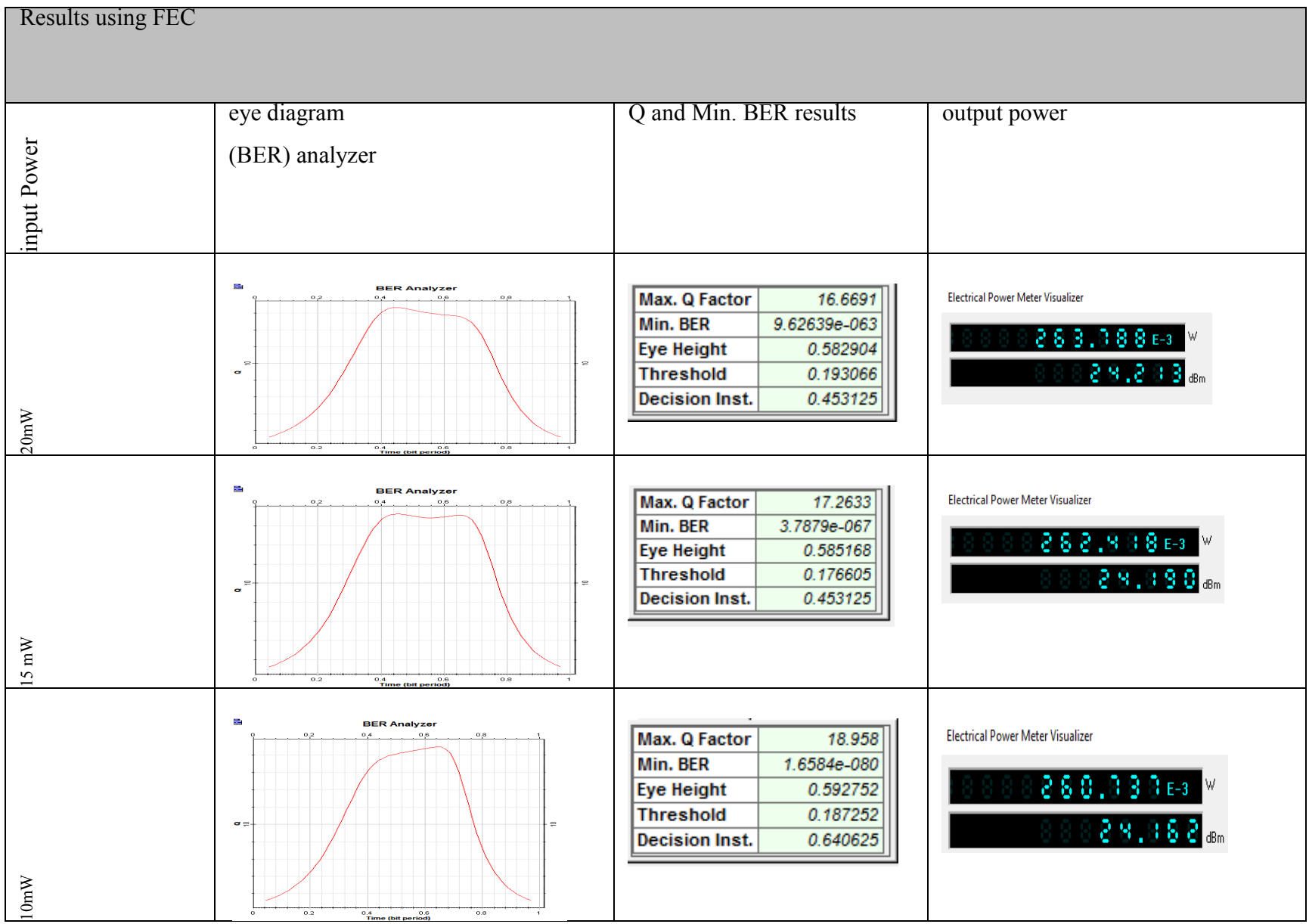


As shown in Table (2) for simulated communication system with two SOAs', placed as pre and post amplifiers, the input parameters values were selected as follows: Signal Input power is 10,15, $20 \mathrm{mWatt}$, Signal wavelength is $1553 \mathrm{~nm}$ (constant Value), Frequency spacing is $0.5 \mathrm{~nm}$ (constant Value), Distance between Tx. and Rx. Was adjusted to 1000,5000 and $10000 \mathrm{~km}$ and Telescope aperture is 15,20 $\mathrm{cm}$. In figure (14) was investigated the max $\mathrm{Q}$ factor with the SOA system, which was at $1000 \mathrm{~km}$ and input power of $10 \mathrm{mWatt}$, but the aperture area of telescope was increased to $20 \mathrm{~cm}$, the $\mathrm{Q}$ factor was found to be 5.48241 and minimum BER was 2.02746E-08.

\subsection{Using the security control of FEC}

In this section it was introduced the Reed-Solomon coding technique to add a security layer on the physical layer used in this design, The design contains the system components as shown in figure (15) using optiwave system version 14.

It was used in this design the forward error correction FEC encoder after the user definite bit sequence, to add a layer of security on the physical layer, at the transmitter FEC was added to assure the efficiency of transmitter by using the ability to compensate the lost bits due to any system noise, by the complex algorithm of RS coder, this is done by sending each character multiple times, and the receiver checks the presence of each character, If no characters conform to the protocol, the character is rejected and an underscore or blank is displayed in its place. FEC codes are capable of generating bit error rate signals, which are used as feedback to fine-tune the analog receiving signals. The $\mathrm{RS}$ codes are having three parameters (n, $\mathrm{k}$, and $\mathrm{t}) \mathrm{n}, \mathrm{k}$ are the number of samples before and after coding, and $t$ is the number of samples that can be corrected and it is equal to the following equation as in $[11] \mathrm{t}=(\mathrm{n}-\mathrm{k}) / 2$. In this work $\mathrm{n}$ and $\mathrm{k}$ kept constant in the simulator as $(7,2)$ respectively. The EDFA is added to compensate any losses in transmitter and receiver with $10 \mathrm{~m}$ length in each amplifier, also, in the transmitter it was used the NRZ modulator to maintain some kind of security as a part of the NRZ modulator is PCM. The distance between the transmitter and receiver is 10000 $\mathrm{Km}$ and telescope lens diameter was $15 \mathrm{~cm}$ as shown in table (3).

\subsection{The results Using the security control of FEC indicates the following}

when using FEC in the design figure (15), if the input power was $(10 \mathrm{~mW})$ the output power was $(260.737 \mathrm{mWatt}), \mathrm{Q}$ factor was (18.985, and min. BER is $(1.6854 \mathrm{e}-080)$, when input power was $(15 \mathrm{~mW})$ the output power was $(262.418$ mWatt), Q factor was (17.2633) and min. BER was (3.7879e-067), when the input power was $(20 \mathrm{~mW})$ the output power was (263.788 mWatt), Q factor was (16.6691), and $\mathrm{min}$. BER is $(9.6 .2639 \mathrm{e}-063)$.

\section{Conclusion}

It was demonstrated that putting pre and post EDFA in satellite communication system and increase the input power was enhancing the communication system quality and increase the $\mathrm{Q}$ factor and decrees the BER. Increasing the distance between transmitter and receiver telescopes decreased the Q factor and respectively increase the BER, it was demonstrated also that increasing input power increase the $\mathrm{Q}$ factor and decrease BER, the length of fiber in EDFA influence the communication quality negatively until a certain length which is no more effective. Increasing the transmitter and receiver telescopes aperture areas enhance the communication. It was demonstrated that increasing the input bit rate decrees the quality of the communication system. It was shown also that the optimum design for a communication system using EDFA in free space satellite systems apart of $10000 \mathrm{~km}$ is using input power of 20 mWatt and EDFA length is $5 \mathrm{~m}$ and both transmitter and receiver telescopes aperture of $20 \mathrm{~cm}$ will give maximum Q factor in this work. Comparatively, it was shown that using $\mathrm{SOA}$ in satellite communication system in $10000 \mathrm{~km}$ spacing between telescopes was not effective as EDFA even when increasing input power for the SOA. Unlike the EDFA, the SOA gain decrees with increase of input power. Also, in OWC system it was demonstrated that using FEC with EDFA in transmitter and receiver, can increase the security of the system without much affecting the performance, and it was demonstrated that the optimum input power for the transmitter in this design is $20 \mathrm{~mW}$ to get maximum output power.

\section{References}

[1] Modeling and performance study of inter-satellite optical wireless communication system, Conference: Photonics (ICP), 2010 International Conference

[2] Effect of EDFA based Various Optical Amplifier Configurations on IsOWC System; Computational Science and Systems Engineering, ISBN: 978-1-61804-362-7

[3] A review of the configuration and performance limitation parameters in optical amplifiers by MOHAMMAD SYUHAIMI AB-RAHMAN Optica Applicata, Vol. XLIV, No. 2, 2014.

[4] Optical Wireless Transmitting Communications Based Satellite Orbit to Orbit Communication Systems Enhancement with EDFA Amplifiers by Ahmed Nabih Zaki Rashed1* Abd El-Naser A. Mohamed2, Hamdy A. Sharshar3, and Ehab Salah El-dien International Journal of Advanced Research in Computer Science and Electronics Engineering (IJARCSEE) Volume 5, Issue 8, August 2016.

[5] C.R. Giles and E. Desurvire, "Modeling erbium-doped fiber amplifiers," Journal of Lightwave Technology, Vol. 9, N. 2, pp. 271-283, 1991.

[6] www.techpedia.com

[7] GAIN AND NOISE FIGURE PERFORMANCE OF ERBIUM DOPED FIBER AMPLIFIERS (EDFA) by A.Cem ÇOKRAK $1 \&$ Ahmet ALTUNCU, JOURNAL OF ELECTRICAL \& ELECTRONICS ENGINEERING Vol. 4 No. 22004. 